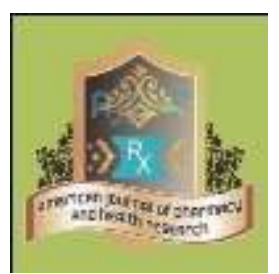

Research Article AMERICAN JOURNAL OF PHARMACY AND HEALTH RESEARCH www.ajphr.com 2018, Volume 6, Issue 04 ISSN: 2321-3647(online)

\title{
Simultaneous UV Spectroscopic Estimation of Cefpodoxime Proxetil and Clavulanic Acid In Tablet
}

\author{
S. Malathi* \\ PSG college of Pharmacy, Department of Pharmaceutical analysis, Coimbatore-641004
}

ABSTRACT

Simple, rapid, accurate and economical method has been developed for the simultaneous Estimation of cefpodoxime proxetil and Clavulanic acid in a synthetic mixture. The linearity was observed in the concentration range of 35 to $63 \mu \mathrm{g} / \mathrm{ml}$ for cefpodoxime proxetil and 10 to 18 $\mu \mathrm{g} / \mathrm{ml}$ for Clavulanic acid. The method is based on the simultaneous equations, absorbance of both the drugs were determined at $232 \mathrm{~nm}$ ( $\lambda$ max of cefpodoxime proxetil), and at $269 \mathrm{~nm}(\lambda$ max of Clavulanic acid). The method was validated in terms of accuracy and precision. The Proposed method was found accurate, reproducible and economical for the routine analysis of both the drugs in synthetic mixture.

Keywords: Cefpodoxime Proxetil, Clavulanic acid, UV spectroscopic analysis, Simultaneous Equation. 


\section{INTRODUCTION}

Cefpodoxime Proxetil (CEF) is a beta lactamase class of bactericidal drug, (Figure.1A) chemically is iso propoxy carbonyl oxy ethyl (f)-(6R, 7R)-7(2 amino 4 thiadyl)-2-2(z) methyl 1 amino)Acetonide)-3 methoxy methyl - 8 - oxo 5 thia -1-azabicyco oct2- one 2-0- carboxyl ate).It is a third generation cephalosporin antibiotic having activity against gram positive and gram negative microorganisms. Clavulanic acid (CLA)is an antibacterial drug,

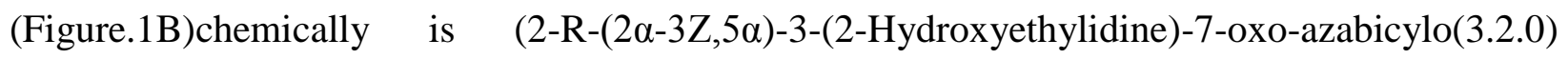
heptanes-2-carboxylic acid (Figure.1 B).It is used as a beta lactamase inhibitor, enhances the activity of penicillin and cephalosporin antibacterial against many resistant strains of bacteria.(12) Many methods have been described in the literature for the determination of cefpodoxime proxetil and Clavulanic acid individually and in combination with other drugs (3-8). However, the present work aims to develop the simultaneous estimation of these drugs in combined dosage form by UV spectroscopic method.

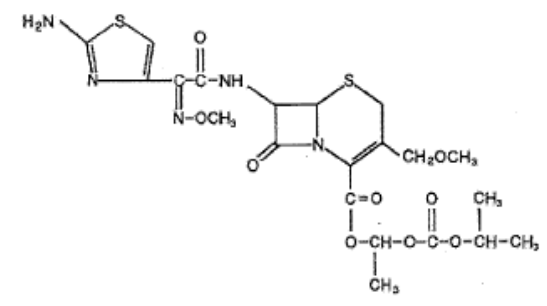

Figure 1(A): Structure of Cefpodoxime Proxetil

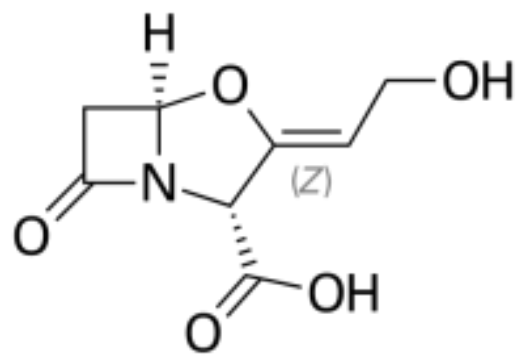

Figure 1(B): Structure of Clavulanic acid

\section{MATERIALS AND METHODS}

\section{Procurement of drug samples and formulation}

Cefpodoxime proxetil was obtained from aurobindo pharm. Ltd, Hyderabad. Clavulanic acid was obtained from Cadila pharmaceutical ltd, Ahmedabad.

\section{Reagents and chemicals used}

Doubled distilled water used throughout the study. Chemicals were purchased from S.D fine chemicals Mumbai. 


\section{Instruments used}

Elico model SL-164 double beam UV/VIS spectrophotometer with a pair of $10 \mathrm{~mm}$ matched quartz cells was used to measure absorbance of the resulting solutions.

\section{EXPERIMENTAL}

\section{Selection of solvent and wavelength}

Standard CLA and CEF stock solution of $10 \mu \mathrm{g}$ and $35 \mu \mathrm{g} / \mathrm{ml}$ concentration was prepared in ethanol respectively. The standard stock solution of CLA and CEF were scanned in the range of $200 \mathrm{~nm}$ to $400 \mathrm{~nm}$ against ethanol as a blank. Maximum absorbance was obtained at $232 \mathrm{~nm}$ and $269 \mathrm{~nm}$ for CEF and CLA respectively. The overlain spectra of CEF and CLA were shown in Figure.2. Absorbance of each solution was measured at both the wavelength $232 \mathrm{~nm}$ and $269 \mathrm{~nm}$.

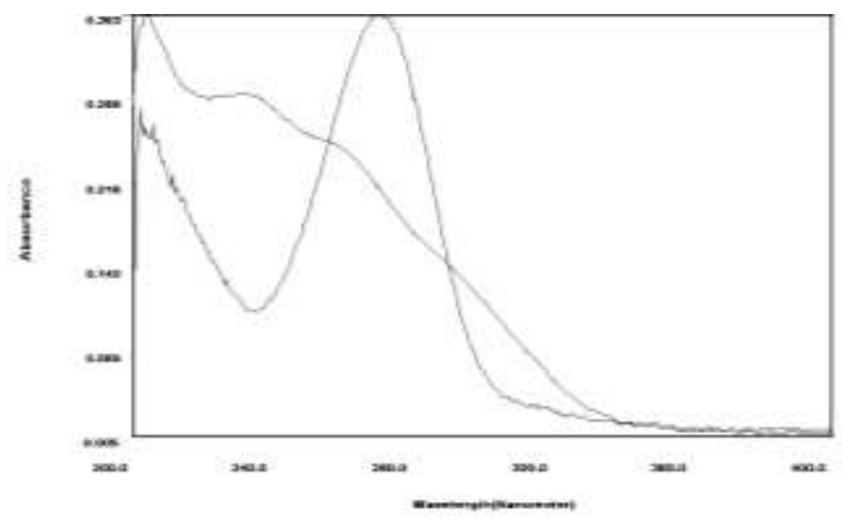

Figure 2: Overlain spectra of Cefpodoxime Proxetil and Clavulanic acid

\section{Analysis of formulation}

Calibration curves were constructed for CEF and CLA by plotting absorbance verses concentration at both the wavelengths. A calibration curve was plotted over a concentration range of 35 to $63 \mu \mathrm{g} / \mathrm{ml}$ for cefpodoxime proxetil and 10 to $18 \mu \mathrm{g} / \mathrm{ml}$ for Clavulanic acid. The synthetic mixture of CLA and CEF was prepared in the ratio of 1:3.5.CEF and CLA tablet (100 $\mathrm{mg}$ and $28.5 \mathrm{mg}$ each) were weighed and quantity equivalent to $10 \mathrm{mg}$ of Clavulanic acid and 35 mg of cefpodoxime proxetil were dissolved in ethanol. Shake it for 20 minutes and make up to the mark by using same. The solution was filtered and further diluted to get concentration $10 \mu \mathrm{g}$ $/ \mathrm{ml}$ and $35 \mu \mathrm{g} / \mathrm{ml}$ of Clavulanic acid and cefpodoxime proxetil respectively. The absorbance of final sample solution was measured against ethanol as a blank at $232 \mathrm{~nm}$ and $269 \mathrm{~nm}$. In the simultaneous equation method concentration of CEF and CLA in the synthetic mixture found out by using simultaneous equations method.

$$
\mathrm{Cx}=\mathrm{A}_{2} \mathrm{ay}_{1}-\mathrm{A}_{1} \mathrm{ay}_{2} / \mathrm{ax}_{2} \mathrm{ay}_{1}-\mathrm{ax}_{1} \mathrm{ay}_{2}
$$




$$
\mathrm{C} \mathrm{y}=\mathrm{A}_{1} \mathrm{ax}_{2}-\mathrm{A}_{2} \mathrm{ax}_{1} / \mathrm{ax}_{2} \mathrm{ay}_{1}-\mathrm{ax}_{1} \mathrm{ay}_{2}
$$

Where $\mathrm{Cx}, \mathrm{C}_{\mathrm{Y}}=$ concentration of CLA and CEF in the sample solution. $\mathrm{A}_{1}, \mathrm{~A}_{2}=$ Absorbance of the Sample solution at $232 \mathrm{~nm}$ and $269 \mathrm{~nm}$ respectively. $\mathrm{ax}_{1}, \mathrm{ax}_{2}=$ absorptivities of CLA at 232,269 $\mathrm{nm}$ respectively.ay ${ }_{1}, \mathrm{ay}_{2}=$ absorptivities of $\mathrm{CEF}$ at 232,269 $\mathrm{nm}$ respectively. The proposed validated method was successfully applied to determine CLA and CEF in the synthetic mixture. (Table.1).The \% recoveries for CEF and CLA obtained were 99.70, 101.59 by simultaneous Equation method. No interference of the excipients with the absorbance appeared. Hence the Proposed method is applicable for the quantitative determination of CEF and CLA in synthetic mixture.

\section{RESULTS AND DISCUSSION}

The analytical method was validated with respect to parameter according to ICH guidelines (9, 10) such as Linearity, Precision, accuracy and stability.

\section{Linearity and range}

\section{Preparation of calibration curve and linearity studies}

CEF was found to be linear at the concentration range of 35-63 $\mu \mathrm{g} / \mathrm{ml}$. Individual standard solutions were scanned using ethanol as blank. The absorbance of this solution was noted at the wavelength $232 \mathrm{~nm}$ and $269 \mathrm{~nm}$ and calibration curve were plotted using concentration Vs absorbance, the calibration graph was shown in Figure.3, 4. CLA was found to be linear at the concentration range of $10-18 \mu \mathrm{g} / \mathrm{ml}$. The absorbance of this solution was noted at the wavelength $232 \mathrm{~nm}$ and $269 \mathrm{~nm}$ and calibration curve were plotted using concentration Vs absorbance, the calibration graph was shown in Figure.5, 6. The values are shown in Table 1 and 2.

Table 1: Absorbance of cefpodoxime Proxetil at selected wavelength

\begin{tabular}{llll}
\hline S. No & $\begin{array}{l}\text { Concentration } \\
\mathbf{2 6 9 n m}(\boldsymbol{\mu g} / \mathbf{m l})\end{array}$ & $\begin{array}{l}\text { Absorbance } \\
\text { at 232nm }\end{array}$ & Absorbance at \\
\hline 1 & 35 & 1.248 & 0.927 \\
2 & 42 & 1.489 & 1.098 \\
3 & 49 & 1.744 & 1.286 \\
4 & 56 & 2.011 & 1.457 \\
5 & 63 & 2.282 & 1.684 \\
\hline
\end{tabular}

Table 2: Absorbance of Clavulanic acid at selected wavelength

\begin{tabular}{llll}
\hline S. No & $\begin{array}{l}\text { Concentration } \\
(\boldsymbol{\mu g} / \mathbf{m l})\end{array}$ & $\begin{array}{l}\text { Absorbance at } \\
\mathbf{2 3 2 n m}\end{array}$ & $\begin{array}{l}\text { Absorbance at } \\
\mathbf{2 6 9 n m}\end{array}$ \\
\hline 1 & 10 & 0.135 & 0.272 \\
2 & 12 & 0.165 & 0.383 \\
3 & 14 & 0.214 & 0.525 \\
4 & 16 & 0.249 & 0.638 \\
\hline
\end{tabular}




\begin{tabular}{llll}
\hline 5 & 18 & 0.296 & 0.748
\end{tabular}

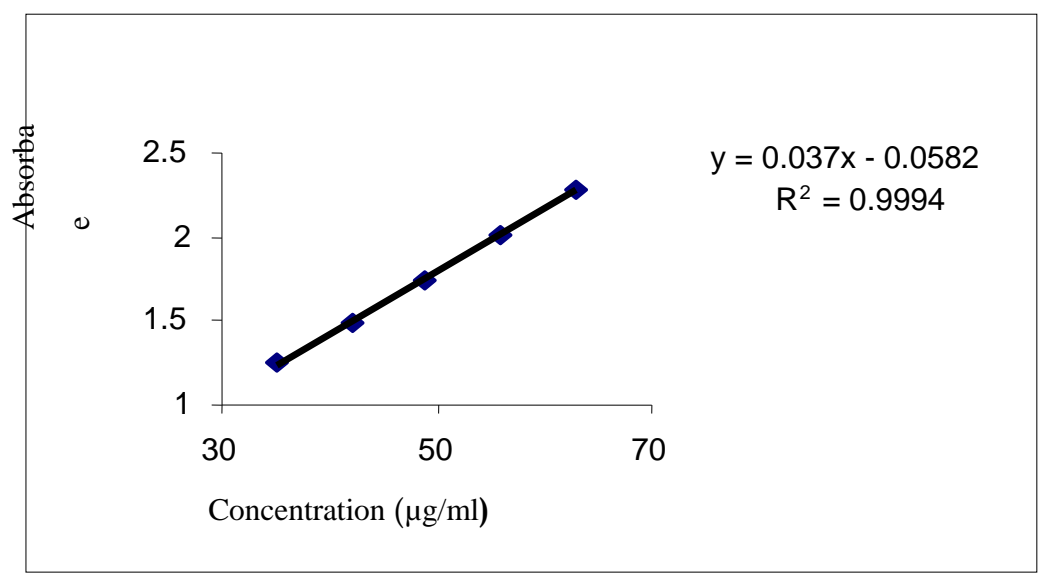

Figure 3: Calibration graph of Cefpodoxime Proxetil at 232nm

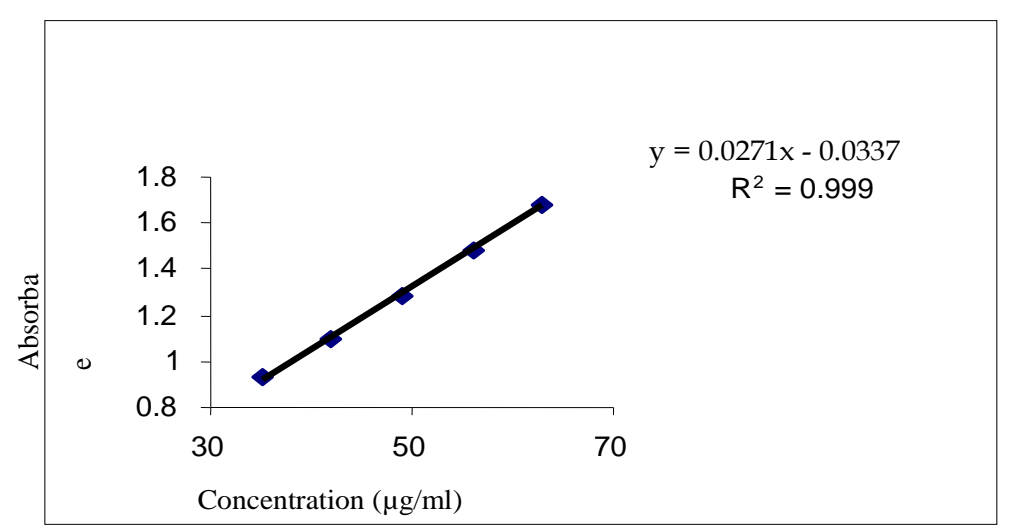

Figure 4: Calibration graph of Cefpodoxime Proxetil 269nm

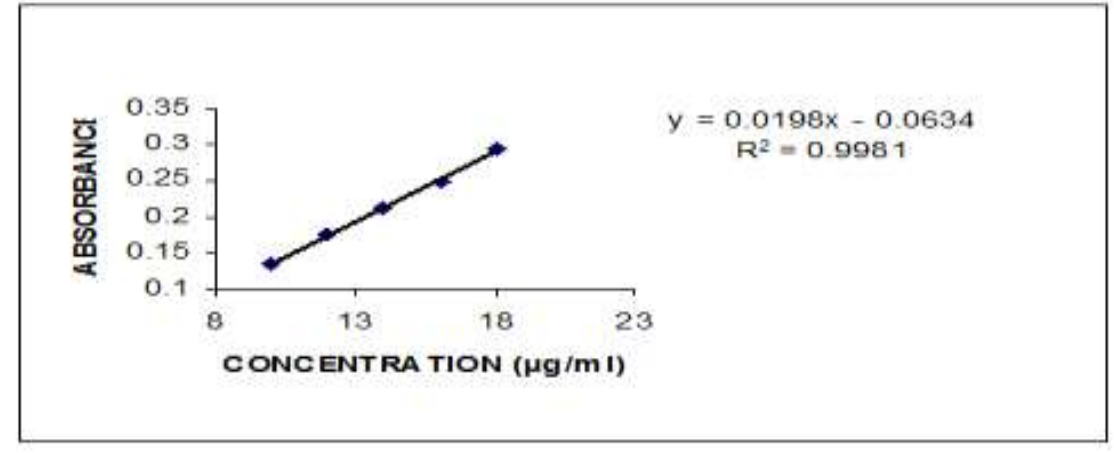

Figure 5: Calibration graph of Clavulanic acid at $232 \mathrm{~nm}$ 


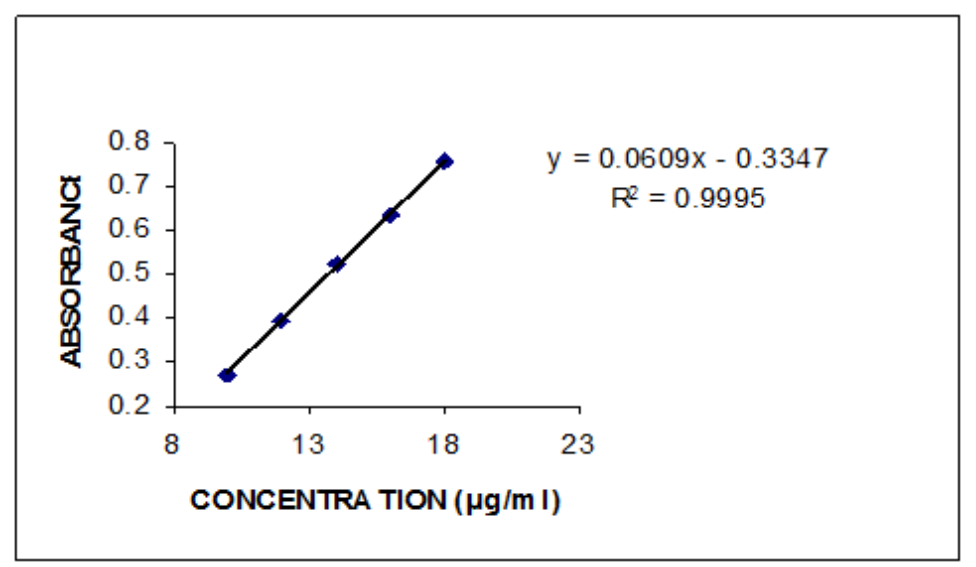

Figure 6: Calibration graph of Clavulanic acid 269nm

\section{PRECISION}

Precision of the method was demonstrated by, 1.Intraday precision 2.Interday precision

\section{Intraday precision}

Intraday precision was found out by carrying out analysis of standard drug solution at three different concentrations in the linearity range for three times on the same day and \% RSD was calculated.

\section{Interday precision}

Interday precision was found out by carrying out analysis of standard drug solution at three different concentrations in the linearity range for three day over a period of one week and \% RSD was calculated.

\section{Accuracy}

The results of recovery studies at various levels shows that the recovery is between 99.0 to 102.0 $\%$ (Ideally should be between 98-102\%). It indicates that there is no interference in the analysis of the drug from the excipients in the tablet formulation. The results of recovery studies of the marketed formulation are shown in the following Table 3.

Table 3: Recovery studies

\begin{tabular}{llllll}
\hline S.No & Level & \multicolumn{2}{c}{ \% Recovery } & \%RSD & \\
& & CEF & CLA & CEF & CLA \\
\hline 1 & 50 & 98.85 & 99.70 & 0.109 & 0.170 \\
2 & 100 & 99.70 & 101.59 & 0.103 & 0.424 \\
\hline
\end{tabular}

\section{*RSD of five observations}

\section{Stability}

The sample solution was subjected to stability studies under room condition. Stability was studied looking for any change in absorbance and peak shape when compared to UV spectra of 
freshly prepared solution. The solution store under room temperature was stable upto 3 hours.

\section{Assay}

The tablets were analysed and the results were obtained in the range of 96-99.6\% compared to the label claim. The results of analysis of marketed formulation are shown in Table 4.

Table 4: Analysis of formulation

RSD of five observation

\begin{tabular}{llllll}
\hline S.No & Drug & Amount(mg) & \multicolumn{2}{c}{ \% Label claim } & \%RSD \\
& & & Labelled & Found & \\
\hline $\mathbf{1}$ & CEF & 100 & 98.8 & 98.8 & 0.212 \\
$\mathbf{2}$ & CLA & 28.5 & 29.0 & 101.11 & 0.918 \\
\hline
\end{tabular}

\section{CONCLUSION}

Thus the method developed in the present investigation is simple, sensitive and not time consuming. This method is novel and can be employed for routine analysis in quality control analysis. The described method is giving accurate and precise results for the determination of CEF and CLA in mixture in marketed formulation.

\section{ACKNOWLEDGEMENT}

The author thanks aurobindo pharm. Ltd, Hyderabad, Cadila Mumbai for providing gift sample for this work.

\section{REFERENCES:}

1. Sean C.Sweetman. Martindale the complete drug reference. $33^{\text {rd }}$ edition., pharmaceutical Society of Great Britain publication; 2002:172-3.

2. Maryadelej.o Neil, Ann smith, Patricia E. Hecklemann. Themerck index., 13th edition., Merck Research laboratories; 1957:2364.

3. Darji B.H, Shah N.J, Patel A.T, Patel N.M. Development and validation of HPTLC method for the estimation of cefpodoxime Proxetil. Indian J Pharm Sci 2007; 69:3313.

4. Shah P.B, Pundakrikakshudu K. Spectroscopic method for the determination of Cefpodoxime proxetil. Indian drugs 2005; 42(2): 94-7.

5. Yoon KH, Lee SY, Jong W, Park S. Simultaneous determination of amoxicillin and Clavulanic acid in human plasma by HPLC-ESI Mass spectrometry. J Chromatograph B 2004; 813:121-7.

6. Shah PB, Pundakrikakshudu K. RP-HPLC for the determination of cefpodoxime proxetil. Indian Drugs 2006; 43:126-128. 
7. Kakumanu VK, Arora VK, Bansal AK. Development and validation of isomer specific RP HPLC method for quantification of cefpodoxime proxetil. J Chromatograph B 2006; 835:16-20.

8. CampusF, Deslandes A, Harcouet L, Farinotti R. High performance liquid chromatographic method for the determination of cefpodoxime level in plasma and sinus mucosa. J Chromatogr B Biomed Appl 1994; 656:383-388.

9. International Conference on Harmonization Guidance for Industry, In: Q2A Text on Validation of Analytical Methods, Switzerland. IFPMIA. 1994; pp. 1-4.

10. International Conference on Harmonization Guidance for Industry, In: Q2B Text on Validation of Analytical Methods, Switzerland. IFPMIA. 1996; pp. 1-8.

AJPHR is

Peer-reviewed monthly

Rapid publication

Submit your next manuscript at editor@ajphr.com / editor.ajphr@gmail.com 